\title{
BIOTECHNOLOGICAL TOOLS IN HUMAN HEALTH - DIAGNOSTIC, PROPHYLACTIC AND TREATMENT PERSPECTIVE
}

\author{
E. Rubika \\ B.Tech (Biotechnology) student, \\ Institute of Fisheries Biotechnology, \\ IFPGS Campus, Tamil Nadu Dr.J.Jayalalithaa \\ Fisheries University, OMR Campus, Vaniyanchavadi \\ Chennai-603103, Tamil Nadu, India
}

\author{
Dr. Suresh, E, M.F.Sc, Ph.D. \\ Assistant Professor \& Head, Department of FGB \\ Institute of Fisheries Post Graduate Studies (IFPGS) \\ Tamil Nadu Dr.J.Jayalalithaa Fisheries University, \\ OMR Campus, Vaniyanchavadi \\ Chennai-603103, Tamil Nadu, India
}

\author{
Dr. Kathirvelpandian, A, M.F.Sc, Ph.D. \\ Associate Professor \& Head, Department of Fisheries Biotechnology, \\ Institute of Fisheries Post Graduate Studies (IFPGS) \\ Tamil Nadu Dr.J.Jayalalithaa Fisheries University, \\ OMR Campus, Vaniyanchavadi \\ Chennai-603103, Tamil Nadu, India
}

\begin{abstract}
Biotechnology possesses immense utility in human health management. Among the biotechnological tools, biomarkers plays an important role in early diagnosis of disease condition, identifying drug delivery mechanism and monitoring of therapy outcomes By means of therapeutic proteins, biotechnology helps in improving the immunity in the patients. Recombinant technology is immensely useful in the production of therapeutic proteins for medical use. Similarly, development of DNA vaccines provides effective protection against the diseases such as polio, TB, small pox, etc., thereby contributing effectively in human health management.
\end{abstract}

Key words: Human health, Biomarkers, molecular diagnostics, therapeutic protein, vaccines.

\section{INTRODUCTION}

Infectious diseases cause major impact in the human health worldwide and also affect world economy. Infectious diseases can be caused by the microorganisms such as viruses, bacteria, parasites and fungi. Fortunately, most of the infectious diseases could be detected in early stages by using biomarkers to reduce the mortality rate (Hwang,H., et al 2018). Biotechnology leads an important role towards managing human health in effective manner. Biomarkers are used in many scientific fields and are used in various ways and purposes in the medical field. Biomarkers provide valuable information about disease condition at the initial level itself enabling treatment for early prognosis. Examples are temperature is an indicator for fever, blood pressure is for stoke and $\mathrm{C}$ - reactive protein is for inflammation. Modern Biotechnology offers biomarkers for diagnostic purposes; vaccines as prophylactic measure and therapeutic proteins for treatment purposes (Gupta, A., \& Chaphalkar, S. R, (2016)).

\section{BIOMARKERS}

The main role of the biomarker is to help the medical field by means of early diagnostics, disease prevention, drug target identification, drug response, etc., Biomarker is defined as characteristics that is objectively measured and evaluated as an indicator of normal biological process, pathogenic processes, or pharmacologic responses to therapeutic interventions $(\mathrm{NIH}$, 1998). The aim of biomarker is to study about disease of the patients for further outcome. Biomarkers related to diseases are prognostic and predictive ones. Prognostic biomarkers are type of biomarkers which can suggest the outcome of a disease in an untreated individual. Predictive biomarker is used to identify the patients who are responding positively to a given treatment (Ballman, K. V, (2015)). Drug related biomarker exhibit the effective drug and its interaction in patients. Biomarkers are specifically cells, molecules, gene product, enzymes and hormones. The discovery of new biomarkers is need of the hour to determine endpoint, predict the clinical outcome to therapy and allow the development of new drug (Afzal, H., et al 2016).

\section{DISEASES AND THEIR BIOMARKERS}

Infectious diseases such as encephalopathy, dengue fever, Kawasaki disease and tuberculosis are detected by the biomarker, serum protein marker. Mixed lineage kinase domain-like (MLKL), an important regulator of necroptotic cell death in inflammatory diseases. MLKL is assessed as 


\section{International Journal of Engineering Applied Sciences and Technology, 2020 \\ Vol. 5, Issue 3, ISSN No. 2455-2143, Pages 166-169 \\ Published Online July 2020 in IJEAST (http://www.ijeast.com)}

biomarker in patient's survival in ICU and it was observed that elevated MLKL after three days of admission in ICU had a significant impaired survival in comparison with low MLKL (Vucur et al., 2018). Huang et al., 2018 investigated the biomarkers for dengue viruses by analyzing cytokine profiles in serum for infected patients. It is observed that cytokine profiles could be used as a biomarker for dengue virus. The study revealed that dengue affected patients found the high level of (CXCL9, IP-10, CXCL11, IL-8 and 1L-10 (pro inflammatory cytokine) and low level of CCL17 \&CXCL5. Lee et al., 2017 investigated Kawasaki disease patients the age-stratified cutoff values of serum $\mathrm{N}$ - terminal prohormones of brain natriuretic. The study revealed that age stratified NTproBNP is a useful biomarker for diagonsing of Kawasaki disease Martynova et al ., 2018 studied the kidney performance in nephropathia epidemia cases and identify urinary clusterin as a biomarker of early and late stage of nephropathia epidemica which is a type of hemorrhagic fever with renal syndrome caused by puumala virus infection. (Bueno, J., et al (2018)).

\section{MOLECULAR DIAGNOSTICS}

Every year $40 \%$ death occurs due to infectious and contagious diseases such as AIDS, TB and malaria. Diagnostics is essential to overcome these diseases. Diagnostics results must be accurate, quick because the results can decide about the further observation, treatment and possible vaccines. In modern biotechnology, there are two ways of diagnosis such as self-replicating antibodies produce for a specific antigen (monoclonal antibodies) and DNA probes could be used to attract the complementary gene sequence of the pathogen. For the diagnostics of biomarker the sample material is must. The sample material may be blood, urine or saliva. Nanotechnology is also used to diagnostics the disease which is rapid, accurate and easy to use. Blood sample is placed between two electrodes, coated with gold particle in the presence of probes. If detected, the Gold particle produces detectable signal (i.e. probes anneal to DNA of the pathogen which could produce light). This technical can be done without using any laboratory facilities (Ali, Q., et al 2016). Various diagnostic marker for different type of tests is listed in Table 1.

Table 1. Diagnostic biomarkers for various tests

\begin{tabular}{|l|l|}
\hline Test & Diagnostic biomarker \\
\hline Saliva tests & Saliva protein ACON \& ATPB. \\
\hline Urine test & Allantoin. \\
\hline Cerebrospinal fluid & $\begin{array}{l}\text { Orosomucoid and proteome in } \\
\text { cerebrospinal fluid. }\end{array}$ \\
\hline Blood test & $\begin{array}{l}\text { Activin B, Buspirone challenge test, } \\
\text { cell trend diagnostic test, cytokine } \\
\text { expression, Dysfunction of TCA \& } \\
\text { urea cycles, EBV-encoded DNA }\end{array}$ \\
\hline
\end{tabular}

\begin{tabular}{|l|l|}
\hline & \begin{tabular}{l} 
polymeease \& EBV-encoded \\
dUTPase, electrical impedance, \\
extracellular vesicles, growth \\
differentiation factor 15, \\
immunosignature, metabolomics, \\
microRNA, mitrochondrial energy, \\
production blockage, nano \\
electronics blood based diagnostic \\
biomarker, natural killer cell \\
function, phenylalanine measured via \\
raman microspectroscopy, plasma \\
neuropeptide Y and Ratio of active : \\
in active PKR. \\
\hline Brain imaging \\
\hline Physiological test
\end{tabular}$\quad \begin{array}{l}\text { Hand grip strength and today } \\
\text { cardiopulmonary exercise testing. }\end{array}$ \\
\hline $\begin{array}{l}\text { Combination } \\
\text { method }\end{array}$ & $\begin{array}{l}\text { Blood \& muscle nerves and blood \& } \\
\text { fecal matter. }\end{array}$ \\
\hline ECG test & Short QT interval \\
\hline
\end{tabular}

Source: me-pedia.org.

\section{THERAPEUTIC PROTEIN}

Therapeutic proteins are proteins which are engineered in the laboratory for human health, which also include enzymes and albumin. Therapeutic proteins are highly effective in vivo and possess potential in treating many diseases of human beings (Ozgur, A., \& Tutar, Y, (2013)). They are generally divided into five groups based on the pharmacological properties (a) replacing a protein that is deficient or abnormal; (b) augmenting an existing pathway; (c) providing a novel function or activity; (d) interfering with a molecule or organism; and (e) delivering other compounds or proteins, such as a radionuclide, cytotoxic drug, or effector proteins. Based on the molecular basis, they are classified as antibodybased drugs, Fc fusion proteins, anticoagulants, blood factors, bone morphogenetic proteins, engineered protein scaffolds, enzymes, growth factors, hormones, interferons, interleukins, and thrombolytics. They are prepared using recombinant technology they are experimented for therapy of cancers, immune disorders, infections, and other diseases. They include mainly engineered proteins with bispecific mAbs and fusion proteins, mAbs conjugated with small drugs molecules, optimized pharmacokinetics proteins, are currently under development. (Dimitrov, 2012). The commonly used therapeutic proteins are given in Table 2.

Table 2. Representative therapeutic proteins for disease management in humans 


\begin{tabular}{|l|l|}
\hline Therapeutic protein & Disease \\
\hline Erythropoietin & Anaemia \\
\hline Interleukin & Renal cancer \\
\hline Interferon alpha & Hepatitis C \\
\hline Interferon beta & Multiple sclerosis \\
\hline Interferon gamma & Chronic granulomatous disease \\
\hline Factor 8 \& 9 & Hemophilia \\
\hline Insulin & Diabetes \\
\hline L-glutaminase & Leukemia \\
\hline
\end{tabular}

Source: (Zahid, K., et al 2016 \& Rehman, K., et al 2015)

\section{DRUGS DEVELOPMENT AND TREATMENT}

Drug development \& treatment has been most focusin 66 health sector in the present scenario. Gene therapy \& genetic engineering are the tools mostly used in the development of new products in pharmaceuticals. Synthetic human insulin was the first product of the biotechnology and it was launched in 1982. Recombinant DNA Technology is one of the major tools of biotechnology used in the vaccine development. [8] Vaccines were developed and been in human use for diseases such as polio, TB, small pox, etc., (Zahid, K., et al 2016). The main principle of vaccines is to stimulate the patient's immune [9] system against infectious microorganisms. DNA vaccines for various human diseases are in the clinical trials for human use. [1 Due to the good biocompatibility of plasmid DNA, their cost- [11] efficient production and long shelf life, many researchers are trying to develop DNA vaccine for treatment of infections and [12] cancer, but also autoimmune diseases and allergies (Hobernik [ and Bros, 2018). Gene therapy, human genome project and somatic gene therapy are precursors of treatment in medical [ biotechnology. Gene therapy contain two type of techniques: germ line gene therapy, changes are made in DNA in germ line of the cell. Stem cell gene therapy which is worked by altering the stem cell. These techniques are very complex and it is only [ possible until we know about the genomic and biological information of the patient.

\section{CONCLUSION}

Medical biotechnology provides immense tools for human health care by diagnosis of different disease, drug discovery, drug development and medical treatment. Biomarkers can be used to diagnose onset of the diseases for early treatment. Vaccines are primarily used as prophylactic measure, wherein, therapeutic proteins possess immense efficiency in disease management. However, still major effort to be infused by the scientists to discover new biomarkers, vaccines, therapeutic proteins and nano-based drug delivery mechanism using biotechnological techniques and their approaches.

\section{REFERENCE}

[1] Afzal, H., Zahid, K., Ali, Q., Sarwar, K., Shakoor, S., Nasir, U., \& Nasir, I. A. (2016). Role of biotechnology in improving human health. J Mol Biomark Diagn, 8(309), 2.

[2] Akash, M. S. H., Rehman, K., Tariq, M., \& Chen, S. (2015). Development of therapeutic proteins: advances and challenges. Turkish Journal of Biology, 39(3), 343-358.

[3] Ballman, K. V. (2015). Biomarker: predictive or prognostic?. Journal of clinical oncology: official journal of the American Society of Clinical Oncology, 33(33), 3968-3971.

[4] Cao, Z., Jia, Y., \& Zhu, B. (2019). Bnp and nt-probnp as diagnostic biomarkers for cardiac dysfunction in both clinical and forensic medicine. International journal of molecular sciences, 20(8), 1820.

[5] Dimitrov, D.S., 2012. Therapeutic proteins. In Therapeutic Proteins (pp. 1-26). Humana Press, Totowa, NJ.

6] Evens, R., \& Kaitin, K. (2015). The evolution of biotechnology and its impact on health care. Health Affairs, 34(2), 210-219.

[7] Gupta, A., \& Chaphalkar, S. R. (2016). Role of Biotechnology in Human Health Care. Emergent Life Sciences Research, 2, 67-72.

[8] Hobernik, D. and Bros, M., 2018. DNA vaccines-how far from clinical use?. International journal of molecular sciences, 19(11), p.3605.

9] https://bitesizebio.com/26559/an-introduction-tobiomarkers/.

10] https://en.m.wikipedia.org/wiki/Biomarker_(medicine).

11] https://mepedia.org/wiki/Diagnostic biomarker\#Growth Dif ferentiation_Factor_15.

[12] https://pubmed.ncbi.nlm.nih.gov/28277917/.

[13] https://www.eupati.eu/clinical-development-andtrials/biomarkers/.

14] https://www.news-medical.net/health/What-is-aBiomarker.aspx.

[15] https://www.nursingcenter.com/ncblog/november2019/biomarker.

16] https://www.sciencedirect.com/science/article/pii/B97801280 4659300023 . https://www.biotecharticles.com/OthersArticle/Biotechnology-Its-Techniques-and-Human-Health25.html.

[17]Huang, J., Liang, W., Chen, S., Zhu, Y., Chen, H., Mok, C.K.P. and Zhou, Y., 2018. Serum cytokine profiles in patients with dengue fever at the acute infection phase. Disease markers, 2018

[18] Hwang, H., Hwang, B. Y., \& Bueno, J. (2018). Biomarkers in infectious diseases. 
[19] Lee, S.H., Song, E.S., Yoon, S., Hong, S., Cho, H.J., Yang, E.M., Eom, G.H., Kang, G. and Cho, Y.K., 2017. Usefulness of age-stratified $\mathrm{N}$-terminal prohormone of brain natriuretic peptide for diagnosing Kawasaki disease. Disease markers, 2017.

[20] Martynova, E.V., Maksudova, A.N., Shakirova, V.G., Abdulkhakov, S.R., Khaertynova, I.M., Anokhin, V.A., Ivanova, V.V., Abiola, I.M., Garanina, E.E., Tazetdinova, L.G. and Valiullina, A.H., 2018. Urinary clusterin is upregulated in nephropathia epidemica. Disease markers, 2018.

[21] Mayeux, R. (2004). Biomarkers: potential uses and limitations. NeuroRx, 1(2), 182-188.

[22] Ozgur, A., \& Tutar, Y. (2013). Therapeutic proteins: A to Z. Protein and peptide letters, 20(12), 1365-1372.

[23] Sawyers, C. L. (2008). The cancer biomarker problem. Nature, 452(7187), 548-552.

[24] Strimbu, K., \& Tavel, J. A. (2010). What are biomarkers?. Current Opinion in HIV and AIDS, 5(6), 463.

[25] Vucur, M., Roderburg, C., Kaiser, L., Schneider, A.T., Roy, S., Loosen, S.H., Luedde, M., Trautwein, C., Koch, A., Tacke, F. and Luedde, T., 2018. Elevated serum levels of mixed lineage kinase domain-like protein predict survival of patients during intensive care unit treatment. Disease markers, 2018. 